\title{
An improved surgical procedure to establish a gastroesophageal reflux model with a high incidence of Barrett's esophagus in rats
}

\author{
HUI WEN ${ }^{1 *}$, TAO LIU ${ }^{1,2^{*}}$, HUA LIU ${ }^{3}$, JING-HUA TENG $^{1}$ and SHENG-BAO LI ${ }^{1}$ \\ ${ }^{1}$ Department of Gastroenterology, Taihe Hospital, Hubei University of Medicine, Shiyan, Hubei 442002; \\ ${ }^{2}$ Department of Pathology, People's Hospital of Longhua, Shenzhen, Guangdong 518131; \\ ${ }^{3}$ Department of Thoracic Surgery, Taihe Hospital, Hubei University of Medicine, Shiyan, Hubei 442002, P.R. China
}

Received February 2, 2018; Accepted August 2, 2018

DOI: $10.3892 /$ etm.2018.6712

\begin{abstract}
Barrett's esophagus (BE) is a complication of gastroesophageal reflux disease and is a precursor lesion of esophageal adenocarcinoma. In existing BE models, the incidence of BE is typically low and induction is usually time consuming. In the present study, a gastroesophageal reflux model with a high incidence of BE in rats. Rats were divided into a model group and a sham operation group, and anesthetized with an inhalation anesthesia machine. Stomach-jejunal anastomosis (SJA) and esophagus-jejunal anastomosis (EJA) were simultaneously performed in the model group. The distance between the Treitz ligament and the gastro-jejunal anastomosis was shortened to $3 \mathrm{~cm}$. The distance between the SJA and the EJA was prolonged to $1-1.5 \mathrm{~cm}$. However, $15 / 40$ rats in the model group succumbed to post-surgical complications (mortality rate was $37.5 \%$ ). The weight of surviving rats in the model group was significantly lower compared with the sham group rats post-surgery. Erosions and ulcers were common of the surviving rats in the model group, with an incidence of $80 \%(20 / 25)$. Squamous cell dysplasia was identified in $40 \%(10 / 25)$ of rats in model group. The modified model was well established within 16 weeks. Notably, the modified surgical procedure used enhanced the incidence of BE in rats from $47 \%$ in the EJGJ model (as establish by Zhang) to $100 \%$. To conclude, this model can be used as a reliable animal model for basic research on BE.
\end{abstract}

\section{Introduction}

The incidence of esophageal adenocarcinoma (EAC) has increased 6-fold over the last two decades in the western

Correspondence to: Professor Sheng-Bao Li, Department of Gastroenterology, Taihe Hospital, Hubei University of Medicine, 32 Renmin South Road, Shiyan, Hubei 442002, P.R. China

E-mail: 1ibao@taihehospital.com

${ }^{*}$ Contributed equally

Key words: animal models, gastroesophageal reflux disease, Barrett's esophagus world (1). The prognosis of EAC is extremely poor and the 5-year survival is $<20 \%$ (2). According to the current understanding, Barrett's esophagus (BE) is a well-known precancerous lesion that is caused by long-standing pathologic exposure to gastroduodenal refluxate $(3,4)$. Histopathologically, BE takes place when normal squamous cells of esophageal mucosal cells are replaced with specific columnar cells, with or without intestinal metaplasia (5). Although the majority of patients with gastroesophageal reflux disease do not develop $\mathrm{BE}(6)$, it has been reported that $<5 \%$ of $\mathrm{BE}$ cases progress into EAC (7).

Multiple animal models of BE and EAC have been developed to investigate the mechanism underlying BE formation. Pera et al (8) introduced the first surgical rat model of ECA by inducing chronic duodenogastroesophageal reflux, with exposure to a known carcinogen (2,6-dimethylnitrosomorpholine) in 1989. The surgical procedure used to induce chronic esophageal reflux was an end-to-side esophagojejunostomy with gastric preservation (8). Since then, several animal models with different surgical procedures have been developed (9-16). The construction of these surgical models have included: Esophagojejunostomy and esophagojejunostomy plus total Gastrectomy $(9,11)$, esophagogastroplasty, side-to-side and end-to-side esophagoduodenostomy $(10,11)$ and esophagoduodenostomy with various degrees of gastrectomy (12).

However, the incidence of BE in these models are low and their induction is usually time consuming. It is therefore necessary to identify novel methods to fully elucidate the mechanism underlying BE formation, and its association with EAC. The purpose of the present study was to introduce an improved procedure in establishing a gastroesophageal reflux model with a high incidence of $\mathrm{BE}$ in rats. A number of modifications to the surgical procedure developed by Zhang et al (17) were made in order to achieve a greater occurrence of BE within 25 weeks.

\section{Materials and methods}

Animals. In total, 50 specific pathogen-free female Sprague Dawley rats (35 weeks old; weight, $350 \pm 10 \mathrm{~g}$ ) were purchased from the Laboratory Animal Center of Hubei University of Medicine (Shiyan, China). All rats were housed in a controlled 
environment (temperature, $22 \pm 2^{\circ} \mathrm{C}$; humidity, $60 \pm 5 \%$; air renovations/h: 15; light cycle/h: 12/12) and had access to water and food. Animal care and experimental protocols were approved by the Animal Research Ethical in Hubei University of Medicine. Rats were allowed to acclimatize for at least 1 week prior to surgery. Rats were randomly divided into two groups: The model group $(n=40)$ and the sham operation group $(\mathrm{n}=10)$. Rats were fasted for $24 \mathrm{~h}$ prior to surgery.

Anesthesia methods. Anesthesia ventilation with isoflurane inhalational anesthetic (Datex-Ohmeda, Inc., Madison, Wisconsin, USA) was performed as follows: The ventilator's oxygen pressure was adjusted to a controlled level at $0.5 \mathrm{MPa}$. Isoflurane was used for induction (3\%) and maintenance (1.5-3\%). Rats were placed into a closed induction-box and the anesthetic flow was switched to the 5th gear. Following 1-2 min of exposure, the rats were induced into a coma. Subsequently the rats were then positioned on the operation table, the ventilator mask was quickly fixed and the anesthetic flow was switched to the 1st gear simultaneously. The breathing was slow and even for rats, owing to the anesthetic effect (Fig. 1).

Surgical methods. The surgical procedure was performed under aseptic conditions. The limbs of rats were fixed in the supine position. The tongue was retracted from the mouth using a hemostat and fixed to maintain constant smooth breathing. Once the operative field was disinfected with $0.5 \%$ povidone-iodine and paved with a surgical drape, an incision into the abdominal cavity was made at the subxiphoid midline abdominal peritoneum. The incision was roughly $4 \mathrm{~cm}$ in length. In the model group, the stomach was exposed and raised with ophthalmic tweezers. The esophagus was exposed and the liver-stomach ligament was carefully cut with an ophthalmic hemostat. The Vagus nerve was carefully protected during this process. The cardia and esophagus were separately ligated with a 3.0 suture near the cardia; the two ligations were $3 \mathrm{~mm}$ apart. The esophagus and stomach were cut and separated in intervals along the ligation. The distal esophagus ligature was pulled gently to avoid esophageal retraction within the thoracic cavity. Subsequently, the duodenum and pylorus were carefully exposed. The duodenum was ligated with a 3.0 suture at a distance of $7 \mathrm{~mm}$ to the pylorus and cut at a distance of $5 \mathrm{~mm}$ to the pylorus. Following this, the stomach was flushed twice with iodine water (1:2 ratio of iodine and saline). Additionally, the jejunum was exposed $3 \mathrm{~cm}$ underneath the Treitz ligament and the pylorus and jejunum were sutured with a 6.0 suture needle on the upper part of jejunum. The gastro-jejunal anastomotic stoma was 5-6 $\mathrm{mm}$ in length. The oblique incision was prepared in the lower esophagus with a scalpel. An oblique esophageal and jejunal incision was sutured with a 6.0 suture needle for the entire layer on the upper jejunum. The esophageal-jejunal anastomotic stoma was 3-4 $\mathrm{mm}$ in length. The distance between the two anastomotic stoma was $1-1.5 \mathrm{~cm}$. Finally, the abdominal cavity was flushed with a sterile gauze and closed. A diagram of the surgical procedure is indicated in Fig. 2. In the sham group, the abdominal cavity was incised, opened and closed $10 \mathrm{~min}$ thereafter. Following surgery, the anesthesia ventilator was
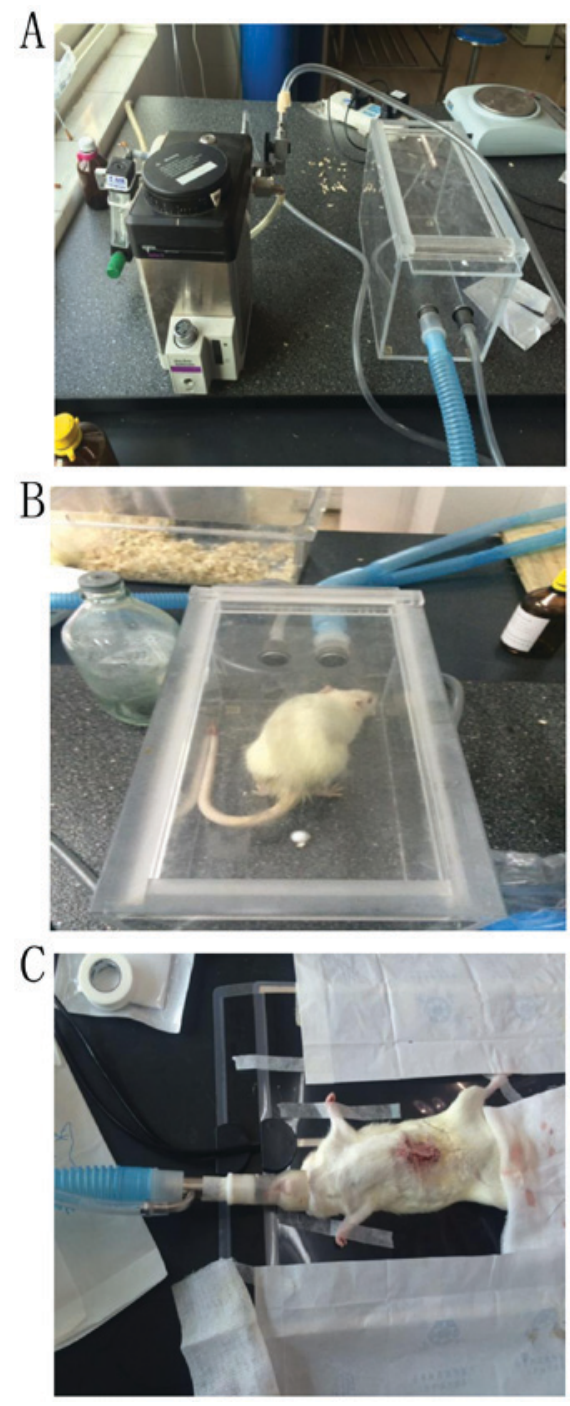

Figure 1. (A) Anesthesia ventilator used for the animal experiments. (B) A rat in the closed induction-box. (C) A ventilator mask was placed on a rat for maintenance anesthesia.

turned off and the respirator mask was quickly removed. Rats were fasted for $24 \mathrm{~h}$ post-surgery and were supplied with 5\% dextrose and $0.9 \%$ saline (1:1) mixture and purified water. The incision was disinfected with iodine once a day in week 1 following the surgery and the rats were caged together (4-5 rats per cage) 10 days following this.

General postoperative condition. Following the surgery, physiological indices of rats, including water intake, food intake, body weight, stool and mental status were recorded. The rats were sacrificed 16 weeks post-surgery and $3-\mathrm{cm}$ tissue specimens of the esophagus and 0.4- $\mathrm{cm}$ jejunum specimens surrounding the esophagus-jejunal anastomosis were collected and cut longitudinally. Gross morphological observations of the esophagus were made simultaneously. The specimens were fixed in $10 \%$ neutral-buffered formalin for $24 \mathrm{~h}$ at $4^{\circ} \mathrm{C}$, then processed and embedded in paraffin. Following routine staining, with hematoxylin $(5 \mathrm{~min})$ and eosin $(2 \mathrm{~min})$ at room temperature, histological changes were observed under an optical microscope (magnification, x100 and x200; Olympus Corporation, Tokyo, Japan). 
A

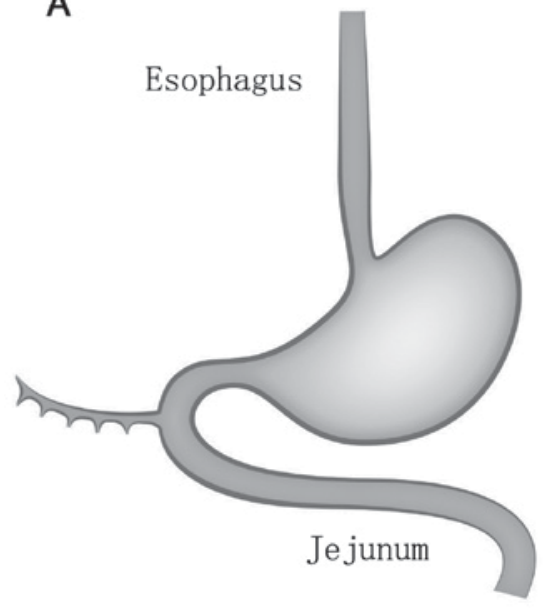

B

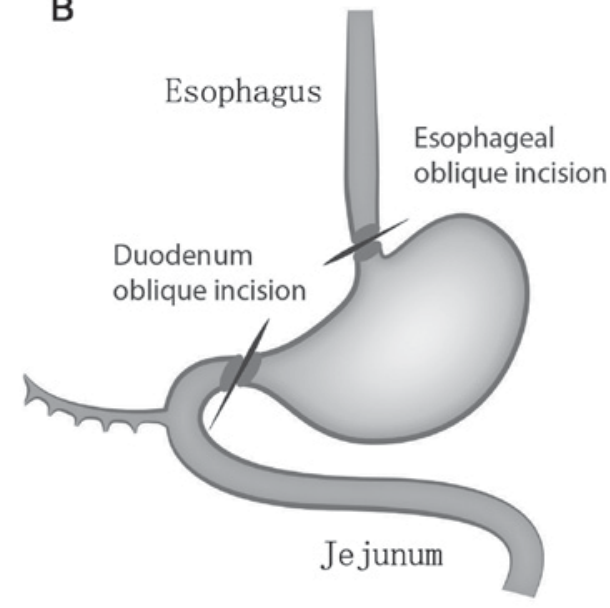

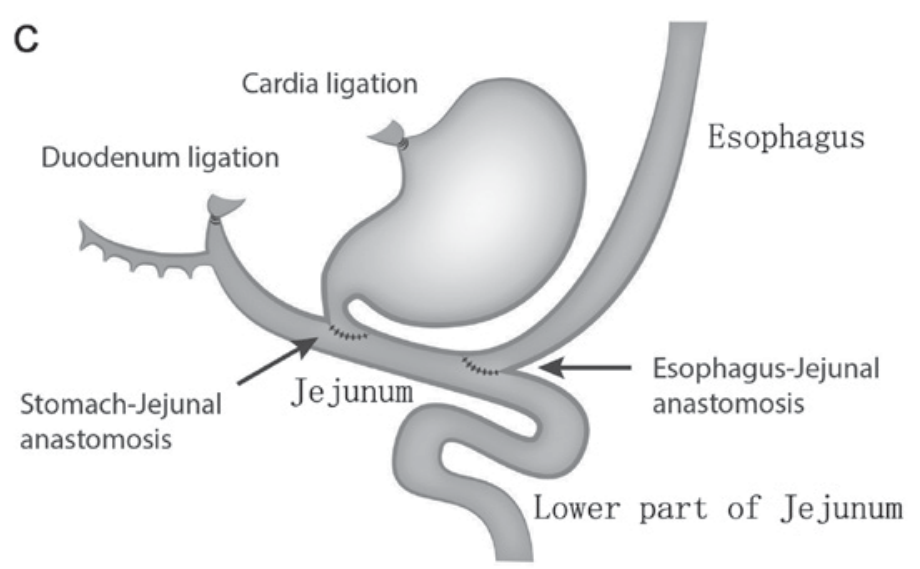

Figure 2. Diagramatic representations. (A) Normal structure of the esophagus, stomach and jejunum. (B) Diagram of the surgical incisions. Cardia and esophageal sphincter were ligated near the cardia. The esophagus and stomach were incised and separated at intervals along the ligation. The duodenum was ligated with 3.0 suture at a distance of $7 \mathrm{~mm}$ to the pylorus and subsequently incised at a distance of $5 \mathrm{~mm}$ to the pylorus. (C) Diagram of the anastomosis surgical procedure. The jejunum was exposed $3 \mathrm{~cm}$ underneath the Tveitz ligament. The pylorus and the jejunum were sutured with a 6.0 suture needle on the upper part of jejunum. Oblique esophageal and jejunal incisions were sutured with a 6.0 suture needle in the entire layer on the upper jejunum. The distance between the two anastomotic stoma was $1-1.5 \mathrm{~cm}$.

Histopathological evaluation. Histopathological evaluation was performed according to Miwa et al (11) and standards proposed by the American College of Gastroenterology (18). Inflammation was defined as the infiltration of inflammatory cells into epithelial tissue, including neutrophils and lymphocytes, with or without esophageal tissue edema. Epithelial hyperplasia was defined as the thickness of the esophageal epithelium increasing more than twice of the normal thickness. Proliferation of the basal cells was defined as the thickness of the squamous basal layer increasing to $>15 \%$, or with an organizational cyst. An ulcer was defined as an epithelial defect, with inflammatory cell infiltration. Squamous epithelial dysplasia was defined as the esophageal mucosa consisting of squamous cells and increased mitotic nuclear staining. Furthermore, BE was defined as the replacement of squamous epithelium by columnar epithelium, with or without metaplasia to the columnar epithelium and esophageal adenocarcinoma was defined as mucinous adenocarcinoma with submucosal tissue infiltration.

Statistical analysis. SPSS 19.0 (IBM Corp., Armonk, NY, USA) was used for statistical analysis. One-way Analysis of variance followed by the Dunnett's post hoc test and $\chi^{2}$ tests were used to compare enumeration data. $\mathrm{P}<0.05$ was considered to indicate a statistically significant difference.

\section{Results}

Rat survival. All rats in the sham group survived. A total of 15 rats in model group succumbed to complications; the mortality rate was $37.5 \%$ (15/40). The majority of fatalities occurred in the first 3 days following the surgery and the mortality rate peaked on the day 3 . The causes of fatality were attributed to surgical complications, including bleeding, obstruction and necrosis (Table I). The number of rats in each group at each time point were presented in Fig. 3.

Drinking and eating results of rats. Water and food intake of each rat was recorded for 10 consecutive days following the surgery. Rats in the sham group were able to eat and drink as normal. Rats that drank and ate little in the model group did not survive. However, the rats that drank and ate normally in model group survived. There was no significant 
Table I. Causes of fatality in rats at different post-surgical time points.

\begin{tabular}{llll}
\hline Variable & \multicolumn{1}{c}{ Day 0-3 } & Day 4-7 & Week 2-3 \\
\hline Causes of fatality (number) & Bleeding in surgery (1) & Week 4-16 \\
& $\begin{array}{l}\text { Mechanical intestinal } \\
\text { obstruction (1) }\end{array}$ & $\begin{array}{l}\text { Aspiration } \\
\text { pneumonia (1) }\end{array}$ & $\begin{array}{l}\text { Aspiration } \\
\text { pneumonia (2) }\end{array}$ \\
& Anastomotic obstruction (4) & & \\
& Gastric ischemic necrosis (1) & & 4 \\
& Anastomotic leak (1) & & \\
Tross hematuria (1) & 9 & 2 & 0 \\
\hline
\end{tabular}
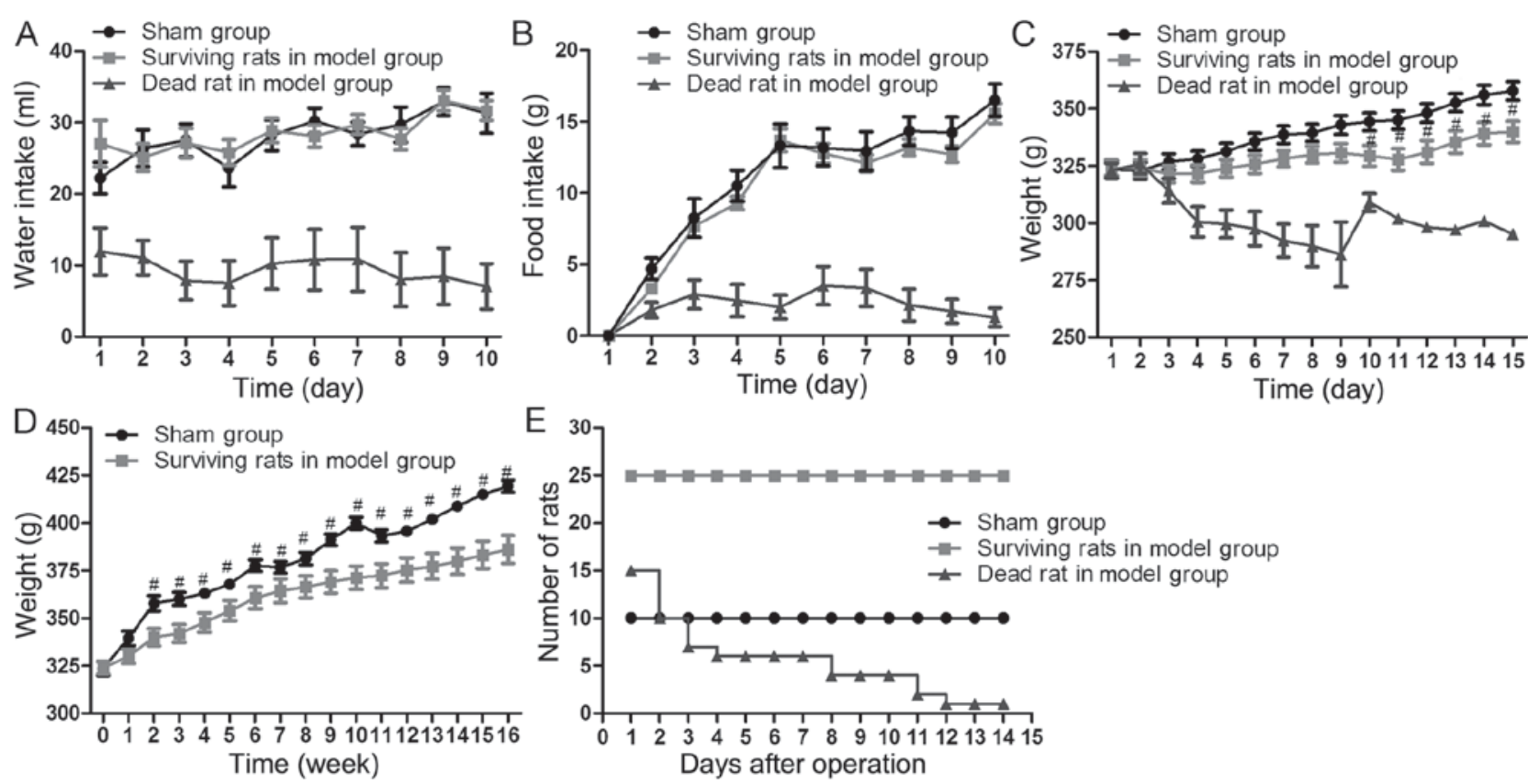

Figure 3. Changes of water, food intake and body weight following the surgical procedure. (A) Changes of water intake and (B) food intake 10 consecutive days following the surgical procedure. (C) Changes of body weight 15 consecutive days following the surgical procedure. (D) Changes of body weight 2-16 weeks following the surgical procedure. (E) The number of rats in each group 14 consecutive days following the surgical procedure. (A and B) Rats in sham group were able to drink and eat normally. Rats that drank and ate little in the model group did not survive; however, rats that drank and ate as normal in the model group survived. There was no significant difference in drinking and eating of those surviving rats between the sham and model group $(\mathrm{P}>0.05)$. (C) The weight of rats in the model group significantly decreased at 10-14 days post-surgery compared with the sham group ( $\mathrm{P} \leq 0.0031)$. (D) Furthermore, the weight of rats in model group gradually increased 2-16 weeks post-surgery; however, the weight of those surviving rats in the model group was still significantly lower than that of the sham group at the end of the 16 weeks $(\mathrm{P}=0.0194) .{ }^{\prime \prime} \mathrm{P}<0.05$. vs. the sham group.

difference in drinking $(\mathrm{P} \geq 0.325)$ and eating $(\mathrm{P} \geq 0.234)$ between surviving rats in the sham group and the model group (Fig. 3A and B).

Weight. The body weight of each rat was measured every day for 15 consecutive days post-surgery. From 2 weeks post-surgery to the end of 16 weeks, the weight of each rat was measured every week. The weight of the rats in the model group was significantly decreased 10-14 days post-surgery compared with the sham group $(\mathrm{P} \leq 0.031$; Fig. $3 \mathrm{C})$. The weight of the surviving rats in the model group gradually increased 2-16 weeks post-surgery. However, the weight of surviving rats in the model group remained significantly lower than that of the sham group at the end of the 16 weeks $(\mathrm{P}=0.0194$; Fig. 3D).
Histological changes. BE and inflammation was identified in all surviving rats in the model group (100\%, 25/25) at the end of the 16 weeks; the difference between the sham and model group was statistically significant $(\mathrm{P}<0.01)$. Erosions and ulcers were common and had an incidence of $80 \%(20 / 25)$ in the model group compared with the control group $(\mathrm{P}<0.01)$. Dysplasia of the squamous epithelium was identified in $40 \%(10 / 25)$ of rats in the model group ( $\mathrm{P}=0.018$; Table II and Fig. 4).

\section{Discussion}

Gastroesophageal reflux can lead to esophageal mucosal damage and inflammation (19). The interaction of acid, bile or the mixture of bile and acid reflux, are believed to 
Table II. Histological changes in esophageal tissues.

\begin{tabular}{lccc}
\hline Variable & Sham group, n (\%) & Model group, n (\%) & P-value \\
\hline Number & 10 & 25 & \\
Barrett esophagus & 0 & $25(100)$ & $\mathrm{P}<0.01$ \\
Inflammation & $1(10)$ & $25(100)$ & $\mathrm{P}<0.01$ \\
Erosion or ulcer & 0 & $20(80)$ & $\mathrm{P}<0.01$ \\
Dysplasia of squamous epithelium & 0 & $10(40)$ & $\mathrm{P}=0.018$ \\
Esophageal adenocarcinoma & 0 & 0 &
\end{tabular}
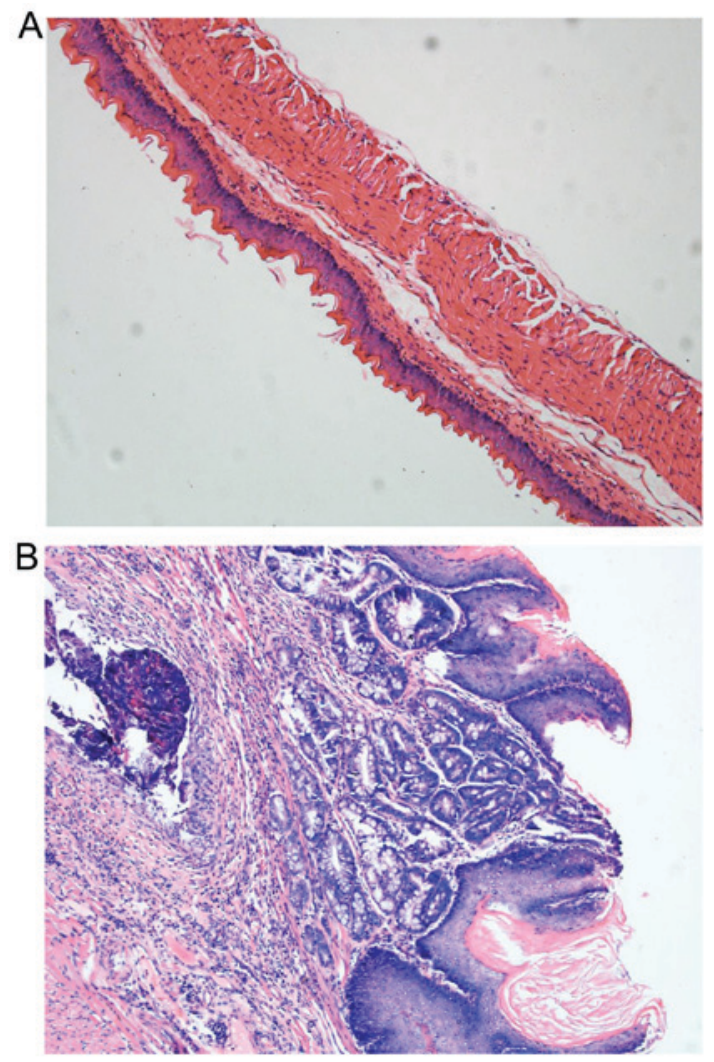

Figure 4. Histological changes of the esophagus. (A) The normal squamous epithelium is the sham group (magnification, x100). (B) Barrett's esophagus of the model group: Squamous epithelium were replaced by columnar epithelium (magnification, x200). Intestinal metaplasia of the columnar epithelium contained brush border absorptive cells and goblet cells. There were several mucosal glands similar to the pyloric glands and Paneth and secretory cells.

serve important roles in the development of BE. Acid and duodenogastroesophageal reflux occurs simultaneously in the majority of reflux episodes (20). Hence, animal models of BE are usually induced by mixed reflux. There are three known mixed-reflux models: Esophagus-duodenum anastomosis (EDA); EJA; and esophagus-jejuna gastro-jejunal anastomosis (EJGJ). In the EDA model, end-to-end anastomosis occurs between the lower esophageal sphincter and the beginning section of the duodenum (1 $\mathrm{cm}$ apart from the pylorus), and the Vagus nerve is protected (21). In the EDA model, gastric secretions, together with duodenal secretions, are refluxed into the esophagus through the anastomosis (21). The EDA model can simulate the reflux state in patients with gastroesophageal reflux disease (GERD) (21). However, the induction of $\mathrm{BE}$ is difficult under this condition because duodenal fluid reflux is reduced (12). In the EJA model, end-to-end anastomosis is made between the lower esophagus and the beginning section of the jejunum, and the Vagus nerve is protected (9). In the EJA model, all fluid from the stomach and duodenum can flow into the lower esophagus. However, this model cannot simulate the true situation in human BE because reflux is too vigorous (20). Subsequently, the EJGJ model created by Zhang et al (17) was adopted in the present study. In this model, gastric juice, which is discharged from the stomach into the jejunum, is mixed with duodenal fluid and then flowed into the lower esophagus due to the short distance between the two anastomoses (15). The EJGJ model simulated the pathophysiological state in human GERD in a superior manner compared with the EDA and EJA models (17). In those models, the Vagus nerve and pylorus were preserved to avoid duodenal fluid reflux into the stomach, which did not affect gastric acid secretion and sustained gastric acid secretion. Modifications to the EJGJ model established by Zhang et al (17) were made in the present study. Firstly, the distance ( $3 \mathrm{~cm}$ in length) between the Tveitz ligament and the gastro-jejunal anastomosis was shortened. Secondly, the distance (10-15 mm in length) between the gastro-jejunal anastomosis and esophagus-jejunal anastomosis was prolonged. It was revealed that the incidence of $\mathrm{BE}$ in the surviving rats reached up to $100 \%$, which was greater than the $47 \%(15 / 32)$ in the EJGJ model established by Zhang et al (17). It was also indicated that 16 weeks were required for BE development, which was shorter than the 25 weeks in the EJGJ model (17). Gastric juice could be mixed well with duodenal fluid because the distance of gastro-jejunal anastomosis and esophagus-jejunal anastomosis was prolonged. Thus, the acidity of fluxed fluid most likely decreased through this improved surgical procedure. Notably, the decreased acidity of fluxed fluid has been proven to contribute to the high incidence of BE in a shorter time (22-27).

The reason for the high mortality rate demonstrated in the present study was due to limited skill of the surgeons in their surgical techniques. In a subsequent study, it was revealed that more practice can reduce the mortality rate of surgery (Wen et al; unpublished data). To increase the esophagus-jejunum anastomotic lumen aperture and avoid obstruction, parallel incisions we changed into an oblique incision at the lower section of the esophagus. Through this modified procedure, only a total of 5 rats succumbed to fatality due to obstruction.

In conclusion, the improved surgical procedure demonstrated in the present study could enhance the incidence of 
$\mathrm{BE}$ in rats. Therefore, this model could be used as a reliable animal model in the basic research of BE.

\section{Acknowledgements}

Not applicable.

\section{Funding}

No funding was received.

\section{Availability of data and materials}

The datasets used and/or analyzed during the current study are available from the corresponding author on reasonable request.

\section{Authors' contributions}

HW designed the current study and performed HE staining. TL took care of the rats, and recorded and analyzed the data. HL performed surgery. JT aided the surgical procedure. SL led the research and provided research funding.

\section{Ethics approval and consent to participate}

Animal care and experimental protocols were approved by the Animal Research Ethical in Hubei University of Medicine (Hubei, China).

\section{Patient consent for publication}

Not applicable

\section{Competing interests}

The authors declare that they have no competing interests.

\section{References}

1. El-Serag HB, Sweet S, Winchester CC and Dent J: Update on the epidemiology of gastro-oesophageal reflux disease: A systematic review. Gut 63: 871-880, 2014.

2. Rubenstein JH and Shaheen NJ: Epidemiology, diagnosis, and management of esophageal adenocarcinoma. Gastroenterology 149: 302-317.e1, 2015.

3. Altorki NK, Oliveria S and Schrump DS: Epidemiology and molecular biology of Barrett's adenocarcinoma. Semin Surg Oncol 13: 270-280, 1997.

4. Isolauri J, Luostarinen M, Isolauri E, Reinikainen P, Viljakka M and Keyriläinen O: Natural course of gastroesophageal reflux disease: 17-22 year follow-up of 60 patients. Am J Gastroenterol 92: 37-41, 1997.

5. Wani S, Rubenstein JH, Vieth M and Bergman J: Diagnosis and management of low-grade dysplasia in barrett's esophagus: Expert review from the clinical practice updates committee of the American gastroenterological association. Gastroenterology 151: 822-835, 2016

6. Phillips WA, Lord RV, Nancarrow DJ, Watson DI and Whiteman DC: Barrett's esophagus. J Gastroenterol Hepatol 26 639-648, 2011.

7. Grant KS, DeMeester SR, Kreger V, Oh D, Hagen JA, Chandrasoma P and DeMeester TR: Effect of Barrett's esophagus surveillance on esophageal preservation, tumor stage, and survival with esophageal adenocarcinoma. J Thorac Cardiovasc Surg 146: 31-37, 2013.
8. Pera M, Cardesa A, Bombi JA, Ernst H, Pera C and Mohr U: Influence of esophagojejunostomy on the induction of adenocarcinoma of the distal esophagus in Sprague-Dawley rats by subcutaneous injection of 2,6-dimethylnitrosomorpholine. Cancer Res 49: 6803-6808, 1989.

9. Fein M, Peters JH, Chandrasoma P, Ireland AP, Oberg S, Ritter MP, Bremner CG, Hagen JA and DeMeester TR: Duodenoesophageal reflux induces esophageal adenocarcinoma without exogenous carcinogen. J Gastrointest Surg 2: 260-268, 1998.

10. Attwood SE, Smyrk TC, DeMeester TR, Mirvish SS, Stein HJ and Hinder RA: Duodenoesophageal reflux and the development of esophageal adenocarcinoma in rats. Surgery 111: 503-510, 1992.

11. Miwa K, Sahara H, Segawa M, Kinami S, Sato T, Miyazaki I and Hattori T: Reflux of duodenal or gastro-duodenal contents induces esophageal carcinoma in rats. Int J Cancer 67: 269-274, 1996.

12. Ireland AP, Peters JH, Smyrk TC, DeMeester TR, Clark GW, Mirvish SS and Adrian TE: Gastric juice protects against the development of esophageal adenocarcinoma in the rat. Ann Surg 224: 358-371, 1996.

13. Mirvish SS: Studies on experimental animals involving surgical procedures and/or nitrosamine treatment related to the etiology of esophageal adenocarcinoma. Cancer Lett 117: 161-174, 1997.

14. Goldstein SR, Yang GY, Curtis SK, Reuhl KR, Liu BC, Mirvish SS, Newmark HL and Yang CS: Development of esophageal metaplasia and adenocarcinoma in a rat surgical model without the use of a carcinogen. Carcinogenesis 18: 2265-2270, 1997.

15. Nishijima K, Miwa K, Miyashita T, Kinami S, Ninomiya I, Fushida S, Fujimura T and Hattori T: Impact of the biliary diversion procedure on carcinogenesis in Barrett's esophagus surgically induced by duodenoesophageal reflux in rats. Ann Surg 240: 57-67, 2004.

16. Su Y, Chen X, Klein M, Fang M, Wang S, Yang CS and Goyal RK: Phenotype of columnar-lined esophagus in rats with esophagogastroduodenal anastomosis: Similarity to human Barrett's esophagus. Lab Invest 84: 753-765, 2004.

17. Zhang T, Zhang F, Han Y, Gu Z, Zhou Y, Cheng Q,Zhu Y, Zhang C and Wang Y: A rat surgical model of esophageal metaplasia and adenocarcinoma-induced by mixed reflux of gastric acid and duodenal contents. Dig Dis Sci 52: 3202-3208, 2007.

18. Shaheen NJ, Falk GW, Iyer PG and Gerson LB; American College of Gastroenterology: ACG clinical guideline: Diagnosis and management of Barrett's esophagus. Am J Gastroenterol 111: 30-50; quiz 51, 2016.

19. Farré R: Pathophysiology of gastro-esophageal reflux disease: A role for mucosa integrity? Neurogastroenterol Motil 25: 783-799, 2013.

20. Vaezi MF and Richter JE: Role of acid and duodenogastroesophageal reflux in gastroesophageal reflux disease. Gastroenterology 111: 1192-1199, 1996.

21. Theisen J, Peters JH, Fein M, Hughes M, Hagen JA, Demeester SR, Demeester TR and Laird PW: The mutagenic potential of duodenoesophageal reflux. Ann Surg 241: 63-68, 2005.

22. Champion G, Richter JE, Vaezi MF, Singh S and Alexander R: Duodenogastroesophageal reflux: Relationship to $\mathrm{pH}$ and importance in Barrett's esophagus. Gastroenterology 107: 747-754, 1994.

23. Marshall RE, Anggiansah A, Owen WA and Owen WJ: Investigation of gastro-oesophageal reflux in patients with an intact stomach: Is oesophageal bilirubin monitoring a useful addition to $\mathrm{pH}$ monitoring? Scand J Gastroenterol 35: 904-909, 2000.

24. Vaezi MF and Richter JE: Synergism of acid and duodenogastroesophageal reflux in complicated Barrett's esophagus. Surgery 117: 699-704, 1995.

25. Sun D, Wang X, Gai Z, Song X, Jia X and Tian H: Bile acids but not acidic acids induce Barrett's esophagus. Int J Clin Exp Pathol 8: 1384-1392, 2015.

26. Cheng P,Li JS, Gong J, Zhang LF and Chen RZ: Effects of refluxate $\mathrm{pH}$ values on duodenogastroesophageal reflux-induced esophageal adenocarcinoma. World J Gastroenterol 17: 3060-3065, 2011.

27. Uno K, Iijima K, Hatta W, Koike T, Abe Y, Asano N, Kusaka G and Shimosegawa T: Direct measurement of gastroesophageal reflux episodes in patients with squamous cell carcinoma by $24-\mathrm{h}$ pH-impedance monitoring. Am J Gastroenterol 106: 1923-1929, 2011.

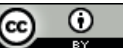

